\title{
Mandibular anterior dental irregularity in a population living a century ago
}

\author{
John Burnheimer DMD, MS* \\ Department of Orthodontics and Dentofacial Orthopedics, University of Pittsburgh, Pittsburgh, PA, USA
}

\begin{abstract}
Objective: The aim of this study is to observe and measure the amount of anterior dental irregularity in an adult 19th century population and compare that to a current adult population.

Methodology: The School of Dental Medicine, University of Pittsburgh possesses a collection of skulls from the late 19th and early 20th century. Most likely those individuals had lived throughout the northeast United States. Twenty-eight skulls were evaluated for the presence or absence of mandibular anterior irregularity and these were compared to modern day alignment values.

Results: $50 \%$ of the observed mandibular dental arches were positive for anterior dental irregularity, which is lower than the current day population in the United States. There was no difference in dental irregularity between males or females in this population. According to Little's Irregularity Index, males over the age of 40 years had the most irregularity.
\end{abstract}

Conclusion: In this population living a century ago, there was less prevalence of anterior dental irregularity than modern research suggests.

\section{Introduction}

Orthodontic treatment has become one of the most sought after health services in modern times. It has been reported that, currently, over $80 \%$ of teenagers in the United States have completed or are undergoing orthodontic treatment [1]. Even as little as fifty years ago, a much smaller percentage of teenagers wore braces.

One of the key reasons for seeking orthodontic care is mandibular anterior malalignment, otherwise known as mandibular incisor crowding, a condition which has been observed in both patients who have and have not had orthodontic treatment. As one ages, patients who have had orthodontic treatment often notice that their once straight teeth become "crooked" [2].

At the University of Pittsburgh, School of Dental Medicine, a collection of skulls from individuals living in the Northeastern United States during the late $19^{\text {th }}$ and early $20^{\text {th }}$ century is on display [3]. These individuals, who lived more than a century ago, would not have undergone modern orthodontic treatment. Therefore, any anterior dental irregularities present would be attributed to normal maturation processes.

This study would yield useful information regarding our understanding of the complex process of mandibular anterior dental irregularity and the prevalence in a population that was not exposed to modern orthodontics.

\section{Methods}

The School of Dental Medicine at the University of Pittsburgh has a collection of skulls which was acquired from a seller in New York City around the 1930's, indicating that these individuals probably resided on the east coast of the United States. These skulls have previously been tagged displaying gender, age (less than or great than 40 years), and ethnicity [3].

For determining mandibular anterior crowding, a set of criteria was established to determine if the skull was eligible for analysis. First, the skull had to have a full complement of adult teeth, exclusive of third molars. Second, the six mandibular anterior teeth had to have intact crowns with no chips or broken fragments. Using these criteria, the mandibular arches of 28 skulls qualified for evaluation, 22 males and 6 females.

To score the severity of crowding of each skull, the linear displacement of the anatomic contact points (as distinguished form the clinical contact points) of each mandibular incisor from the adjacent tooth anatomic point was summed [4]. These measurements were obtained with a dial caliper (Orthopli Corporation, USA) accurate to $0.01 \mathrm{~mm}$. Theoretically, perfect alignment would have a score of 0 .

\section{Data analysis}

Means and standard deviations were calculated for all data. Comparisons were statistically analyzed by using nonparametric tests with the significance level set at $\mathrm{p}>0.05$.

Correspondence to: John Burnheimer DMD, MS, Assistant Professor, Department of Orthodontics and Dentofacial Orthopedics, University of Pittsburgh, Pittsburgh, PA, USA, Tel: 4126488689, Fax: 4126488817, E-mail: Jmb334@pitt.edu

Key words: dental irregularity, dental crowding, little's irregularity index

Received: January 20, 2017; Accepted: February 08, 2017; Published: February 10,2017 


\section{Results}

The prevalence of mandibular anterior malalignment in the observed population of 28 skulls was equal to $50 \%$ as shown in Table 1. Similarly, the percentage of males and females with mandibular anterior malalignment was $50 \%$ (Table 2). When the sample was divided according to sex, the average amount of mandibular anterior discrepancy in males (6.2) exceeded that in females (5.7). When the sample was divided according to age, both over 40 -year-old groups exhibited more crowding than their younger counterparts (Table 3).

\section{Discussion}

The aim of this study is to observe and measure the amount of anterior dental irregularity in an adult $19^{\text {th }}$ century population and compare that to a current adult population. In this $19^{\text {th }}$ century population, the prevalence of mandibular anterior crowding was $17 \%$ lower than that of modern studies, which suggest that $67 \%$ of adolescents will develop mandibular anterior crowding by early adulthood [5].

The realization that less mandibular anterior crowding exited years ago is intriguing and begs the question why does crowding exist at all? The etiology of mandibular anterior crowding is undoubtedly multifactorial with two leading theories being proposed.

The first theory concerns continued mesial movement of the mandibular posterior teeth, as one ages, which then causes anterior crowding. This is an attractive concept as it implies that mandibular anterior crowding cannot be prevented and is just part of aging. Multiple studies have found no clinically significant reduction in mandibular anterior crowding with the removal of third molars or in patients who are congenitally missing third molars [6]. Other theories in this category attribute late mandibular anterior crowding to occlusal forces, eruption patterns or muscle function. These individually or collectively may have some role, but none has been found to play a primary role in late mandibular anterior crowding.

The second theory concerns the equilibrium theory of tooth position which proposes that a stable dentition exists in a state of balance. This balance, where the net resting pressure of the tongue, lips, cheeks, and periodontium equals zero, will be maintained until disrupted. Once disrupted, the teeth will move until a new state of balance is achieved

Table 1. Prevalence of mandibular anterior crowding in the observed population.

\begin{tabular}{|l|c|}
\hline Skulls & \\
\hline With crowding & 14 \\
\hline Without crowding & 14 \\
\hline Percent with crowding & $50 \%$ \\
\hline
\end{tabular}

Table 2. Comparison of mandibular anterior crowding by sex.

\begin{tabular}{|l|c|c|c|}
\hline & Crowding & No Crowding & Percentage \\
\hline Males & 11 & 11 & $50 \%$ \\
\hline Females & 3 & 3 & $50 \%$ \\
\hline
\end{tabular}

Table 3. Comparison of little's irregularity index by age and sex.

\begin{tabular}{|l|c|c|c|}
\hline & Average & SD & $\mathbf{n}=$ \\
\hline Males $>40$ & 6.56 & 2.98 & 8 \\
\hline Males $<40$ & 5.25 & 2.3 & 3 \\
\hline All males & 6.2 & & 11 \\
\hline Females $>40$ & 5.85 & 2.23 & 2 \\
\hline Females $<40$ & 5.48 & & 1 \\
\hline All females & 5.7 & & 3 \\
\hline
\end{tabular}

[7]. The leading concept in this category is the differential mandibular growth theory, which states that when the mandibular growth exceeds the maxillary growth, forces from the maxillary arch and accompanying soft tissues cause uprighting of the mandibular anterior teeth. This movement results in crowding by forcing the incisors to occupy a smaller arch perimeter (Figure 1). Alternate theories in the category suggest that changes in facial muscles or other soft tissues are responsible for the altered equilibrium. However, the correlation between growth changes and mandibular anterior crowding is weak.

As shown in Tables 1 and 2 , there was mandibular anterior crowding in $50 \%$ of the observed adult population from the eastern coast of the United States a century ago, and this was equally divided between males (50\%) and females (50\%). This crowding is $17 \%$ lower than that reported in the literature for modern adults (67\%). Many, but not all, of these skulls had third molars present, however no determination could be made regarding the first theory of mesial movement of mandibular posterior teeth. Obviously, the second theory cannot be applied. Perhaps, the arch perimeter of this century ago population was larger than current adult arch perimeters, thereby resulting in less crowding.

When comparing the observed to a current population using Little's Irregularity Index (LII), both males and females over 40 exhibited more crowding than those under 40 , and all males exhibited more crowding than all females (Table 3 ). The process of mandibular arch constriction that accompanies mandibular anterior crowding seems to continue throughout the third and fourth decades of life. Even those treated by modern orthodontic therapy in adolescence are not resistant to the significant changes in mandibular anterior alignment that occur with aging. Even though the sample size was small, crowding in both the males and females from a century ago would be consistent with current studies which have evaluated long term changes in mandibular anterior alignment [2].

Even though the crowding was comparable in both populations, caution must be exercised in interpreting the data as the sample size was small, particularly the number of female skulls [3]. With a larger sample of skulls, a significant difference may have been found between the observed and current populations. Additionally, the teeth in many of the skulls exhibited some movement in the socket. Other investigators may have stabilized the teeth differently, thereby the LII may have varied from these figures. Finally, these skulls, as part of a collection, may not accurately represent the general population living at that time.

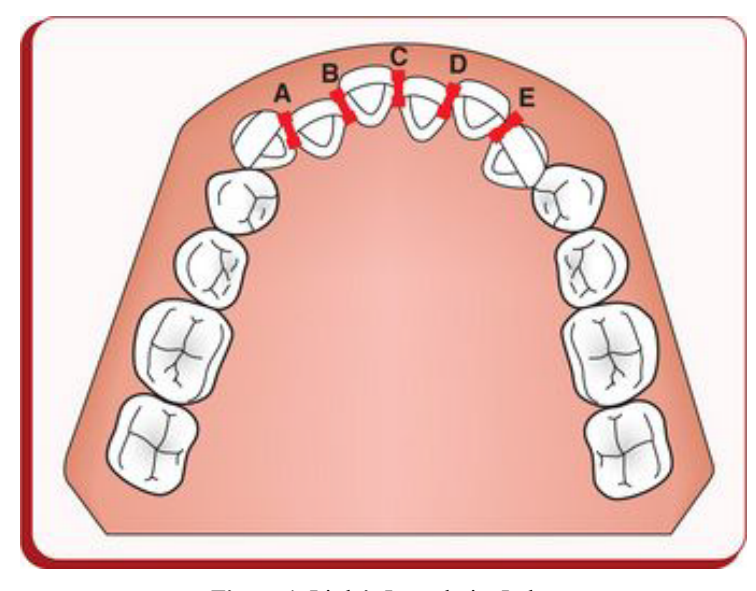

Figure 1. Little's Irregularity Index. 
In conclusion, from this small sample of a population living a century ago, it was observed that the prevalence of mandibular anterior crowding was less than current research suggests, however, the amount of crowding was similar.

\section{References}

1. American Association of Orthodontists (2017) Available at: https://www.aaoinfo.org/ [Accessed 25 January 2017].

2. Little RM, Riedel RA, Artun J (1988) An evaluation of changes in mandibular anterior alignment from 10 to 20 years postretention. Am J Orthod Dentofacial Orthop 93: 423-428. [Crossref]
3. Rose E, Vieira AR (2008) Caries and periodontal disease: insight from two US populations living a century apart. Oral Health Prev Dent 6: 23-28. [Crossref]

4. Little RM (1975) The Irregularity Index: A quantitative score of mandibular anterior alignment. Am J Orthod Dentofacial Orthop 68: 554-563. [Crossref]

5. Sinclair PM, Little RM (1983) Maturation of untreated normal occlusions. Am J Orthod Dentofacial Orthop 83: 114-113. [Crossref]

6. Harradine N, Pearson M, Toth B (1998) The effect of extraction of third molars on late lower incisor crowding: a randomized controlled trial. Br J Orthod 25: 117-122. [Crossref]

7. Proffit WR (1978) Equilibrium theory revisited: factors influencing position of teeth Angle Orthod 48: 175-186.[Crossref]

Copyright: $@ 2017$ Burnheimer J. This is an open-access article distributed under the terms of the Creative Commons Attribution License, which permits unrestricted use, distribution, and reproduction in any medium, provided the original author and source are credited. 